\title{
QUANTITATIVE ASPECTS OF IRON DEFICIENCY IN HYPOCHROMIC ANEMIA
}

\author{
(The Parenteral Administration of Iron) ${ }^{1}$ \\ BY CLARK W. HEATH, MAURICE B. STRAUSS, AND \\ WILLIAM B. CASTLE \\ (From the Thorndike Memorial Laboratory, Second and Fourth Medical Services (Harvard) \\ of the Boston City Hospital; the Department of Medicine and the Department of \\ Tropical Medicine, Harvard Medical School, Boston)
}

(Received for publication August 1, 1932)

Evidence has been accumulating in recent years which suggests that certain forms of hypochromic anemia are primarily due to a deficiency of iron (1), (2), (3). In deficient conditions, generally, the ultimate rôle played by the deficient substance is unknown. This is especially true in the vitamin deficiencies. In the study of the quantitative aspects of iron deficiency the information yielded by the oral administration of iron is of only limited value, because the greater part of the iron so administered leaves the body in the feces. When iron is administered parenterally it is reasonable to believe that only an excess will be excreted. Since much the greater part of the iron in the body is contained in the hemoglobin, and the hemoglobin is the substance in the body apparently most affected in hypochromic anemia, and since the hemoglobin is easily available for accurate determination, it appears practical to study quantitatively this type of deficiency by means of the parenteral administration of iron.

The purpose of the present study is two-fold: first, to describe the dosage of iron which may be given parenterally in hypochromic anemia, and to compare it with the dosage by mouth; secondly, to determine the fate of iron administered parenterally, and establish a quantitative basis for the better knowledge of this type of deficiency. This will lead, it is hoped, to a better understanding of the quantitative aspects of other deficiency disorders.

The study presented here has been made upon seventeen consecutive cases of hypochromic anemia treated with iron administered parenterally. A summary of the clinical data is given in Table 1. The cases were of types known to respond well to iron therapy by mouth. The anemia was either of the idiopathic hypochromic type or was due to chronic blood loss, inadequate diet, previous pregnancies, or combinations of

1 The expenses of the present investigation were borne in part by grants from the J. K. Lilly gift to the Medical School of Harvard University. 


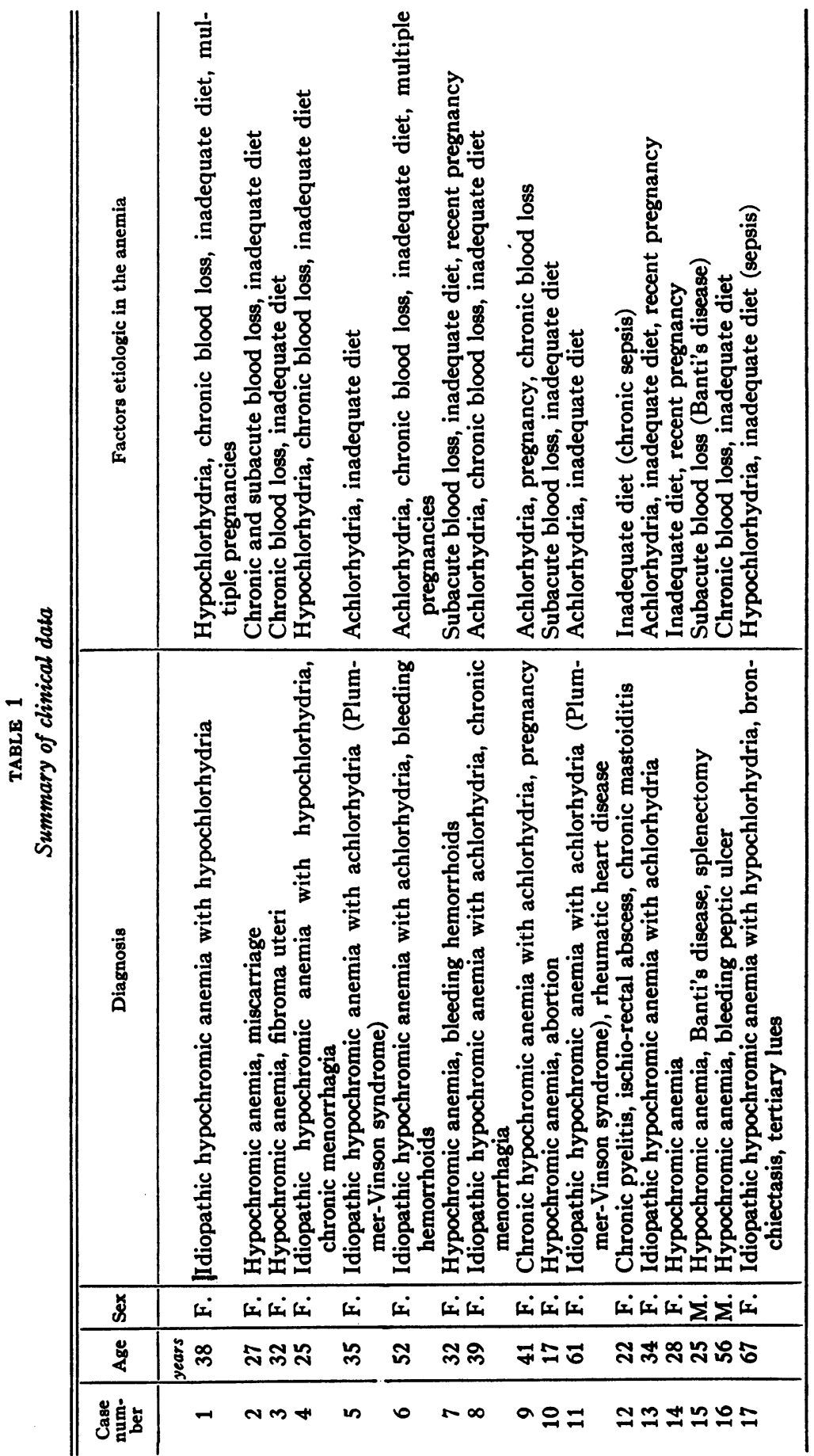


these factors. Complications which significantly inhibit blood formation were absent, such as severe sepsis, severe damage to organs, and carcinoma. Adequate control periods before therapy was instituted were regarded as essential in such a study, and were made in each case.

\section{METHODS}

Blood was taken daily from the ear for reticulocyte counts during the period of close observation. As a rule, every second or third day venous blood was taken for complete blood studies. The blood counts were made with pipettes and counting chambers certified by the U. S. Bureau of Standards. The hemoglobin was determined with the Sahli Haemometer, which had been standardized by determinations of the oxygen capacity of the blood using the Van Slyke apparatus. One hundred per cent hemoglobin was taken as the equivalent of 15.6 grams per $100 \mathrm{cc}$. of blood, or 21 volumes per cent oxygen capacity. Blood volumes were determined upon five cases by the vital red dye method of Rowntree, Brown and Roth (4).

Except in two instances which will be indicated, iron citrate green (N.N.R.) in various dilutions, usually in 10 per cent solution, was used for daily intramuscular or subcutaneous injection. This is a neutralized solution of iron and ammonium citrate with 0.5 per cent quinine and urea hydrochloride as a local anesthetic. The iron and ammonium citrate in this preparation contains approximately 16 per cent of metallic iron. Solutions containing 10 per cent iron and ammonium citrate were used as a rule, but sometimes more dilute solutions were administered. It was given usually in a dose corresponding to from 8 to $32 \mathrm{mgm}$. metallic iron at each injection. Iron and ammonium citrate (brown scales ${ }^{2}$ ) was used orally, usually in a dose of 6 grams daily, corresponding to approximately 1 gram of metallic iron.

Iron in doses of 16 to $32 \mathrm{mgm}$. a day, given parenterally, is very close to the maximum amount of iron tolerated by man. It is attended by disagreeable symptoms, sometimes severe and possibly dangerous. Severe local pain usually follows the intramuscular injection, lasting about twenty-four hours, and much longer if the solution is not neutralized. Immediately following the injection, and for about thirty minutes afterwards, the patient experiences a disagreeable feeling of general warmth, palpitation and sometimes a pressure sensation in the region of the precordium, nausea and frequently vomiting. After the administration of $48 \mathrm{mgm}$. and $80 \mathrm{mgm}$. in two patients, respectively, there were much more severe reactions. Five minutes after the injection there was flushing of the face, engorgement of the neck veins and an appearance of intense anxiety. Vomiting occurred much as it does after the administration of apomorphine. The pulse was rapid and full, the heart sounds loud, and there was moderate hyperpnea. Precautions were especially taken that the solution should not be injected directly into a vein, and yet the rapidity of onset of symptoms suggested this possibility. After one hour the disagreeable symptoms had nearly disappeared. It was thought that such large doses of iron were distinctly dangerous. The injection of $8 \mathrm{mgm}$. of iron a day was attended by more moderate symptoms of the above nature.

2 No significant difference has been found in the effectiveness of brown scales and green scales given orally to patients with hypochromic anemia. 
Comparison of the parenteral dosage with the oral dosage of iron

The first ten cases, after the necessary control period, were given iron parenterally each day for about ten days. On the day following the last injection of iron, the daily oral dose of iron and ammonium citrate was commenced. This method of investigation has been employed successfully (5), (6) to compare, by means of reticulocyte responses, the potency of substances affecting the blood. Following the subsidence of a rise of reticulocytes due to the uniform daily administration of the first substance, a rise of reticulocytes due to the uniform daily administration of the second substance is proof that this second substance, in the quantity given, is more potent than the first in the quantity given, provided that the two are similar in their quality. A summary of the hemoglobin and reticulocyte responses to both parenteral and oral iron therapy is given in Table 2.

Case 1 received a commercial preparation entitled "endocolloidal iron" said to contain $8 \mathrm{mgm}$. of metallic iron in the daily dose. No hemoglobin or reticulocyte response resulted from these injections in this patient. Case 2 was given a commercial preparation of a "colloidal" solution of ferric hydroxide in at least double the maximal dosage recommended by the manufacturers, and attained a moderate reticulocyte rise and a very slow hemoglobin rise. It is possible that the iron given to Case 1 was not in an available form for immediate hemoglobin building, but was merely stored.

The ten cases may be divided into three groups: five cases receiving an equivalent of $8 \mathrm{mgm}$. metallic iron daily, two cases receiving $16 \mathrm{mgm}$. daily, and three cases receiving $32 \mathrm{mgm}$. daily. An illustrative case is shown in Figure 1. Table 3 is a summary of the hemoglobin responses in the ten cases and shows the average percentage of hemoglobin rise per day in the three groups. The smallest average daily rise of hemoglobin occurred with the five patients receiving the smallest amount of iron, namely, $8 \mathrm{mgm}$.; the largest average rise of hemoglobin occurred with the group receiving the largest amount of iron, $32 \mathrm{mgm}$. The average daily rise of hemoglobin of all ten cases during the oral administration of iron was 1.3 per cent, a somewhat smaller rate than for the group receiving $32 \mathrm{mgm}$. of iron parenterally, which was 1.9 per cent. This would seem to indicate that $32 \mathrm{mgm}$. of iron given parenterally was a somewhat more effective dosage than $1,000 \mathrm{mgm}$. of iron given orally.

On the other hand, when the reticulocyte responses are considered, a different state of affairs exists. It will be seen from Table 2 that in all of the cases, except Case 5 and Case 10, a definite reticulocyte response was observed during the period in which iron was administered orally. In Case 5 no reticulocyte counts were made in the second period. In Case 10 the oral administration of iron was commenced before there was a complete subsidence of the reticulocytes, which may have masked a small 


\begin{tabular}{|c|c|c|c|}
\hline \multirow{2}{*}{ 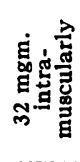 } & \multirow{2}{*}{$\begin{array}{l}\stackrel{\circ}{ } \\
\mathbf{\Xi} \\
\tilde{J}\end{array}$} & 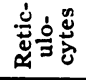 & పี \\
\hline & & 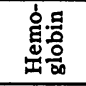 & 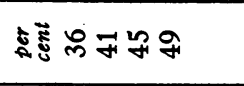 \\
\hline \multirow{2}{*}{ 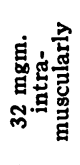 } & \multirow{2}{*}{$\begin{array}{l}\hat{\tilde{y}} \\
\text { Jु }\end{array}$} & 宅造离 & 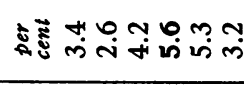 \\
\hline & & 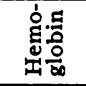 & 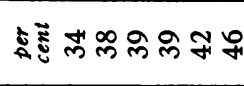 \\
\hline \multirow{2}{*}{ 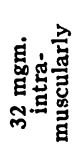 } & \multirow{2}{*}{$\begin{array}{l}\infty \\
\ddot{\nu} \\
\tilde{J} \\
\tilde{J}\end{array}$} & 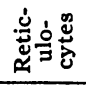 & 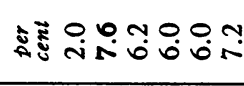 \\
\hline & & 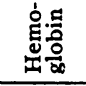 & 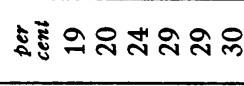 \\
\hline \multirow{2}{*}{ 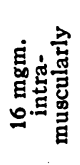 } & \multirow{2}{*}{$\begin{array}{l}\hat{y} \\
\tilde{J}\end{array}$} & 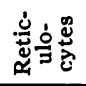 & 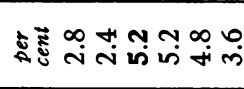 \\
\hline & & 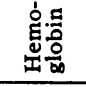 & 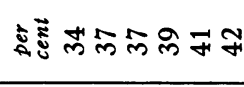 \\
\hline \multirow{2}{*}{ 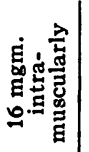 } & \multirow{2}{*}{ 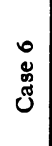 } & 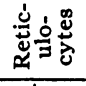 & ¿ \\
\hline & & 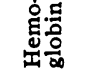 & 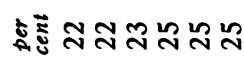 \\
\hline
\end{tabular}

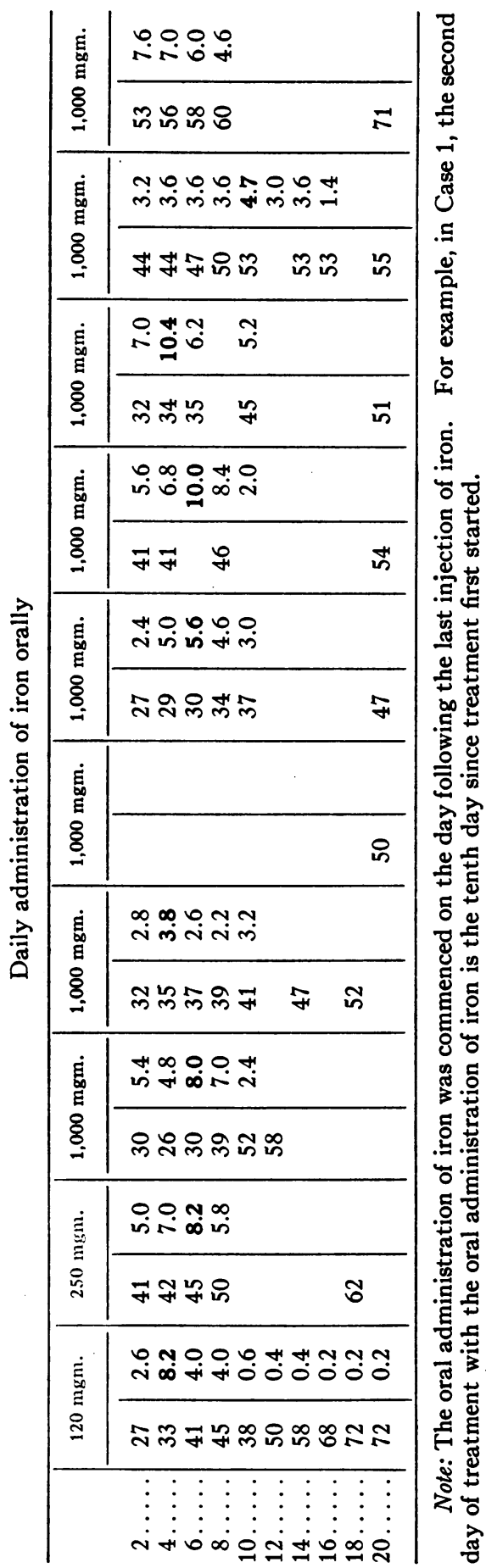


second reticulocyte response. With these two exceptions, the data indicate that the oral dosage of iron in each case was more effective than the parenteral dosage, and it may be concluded from this reticulocyte data

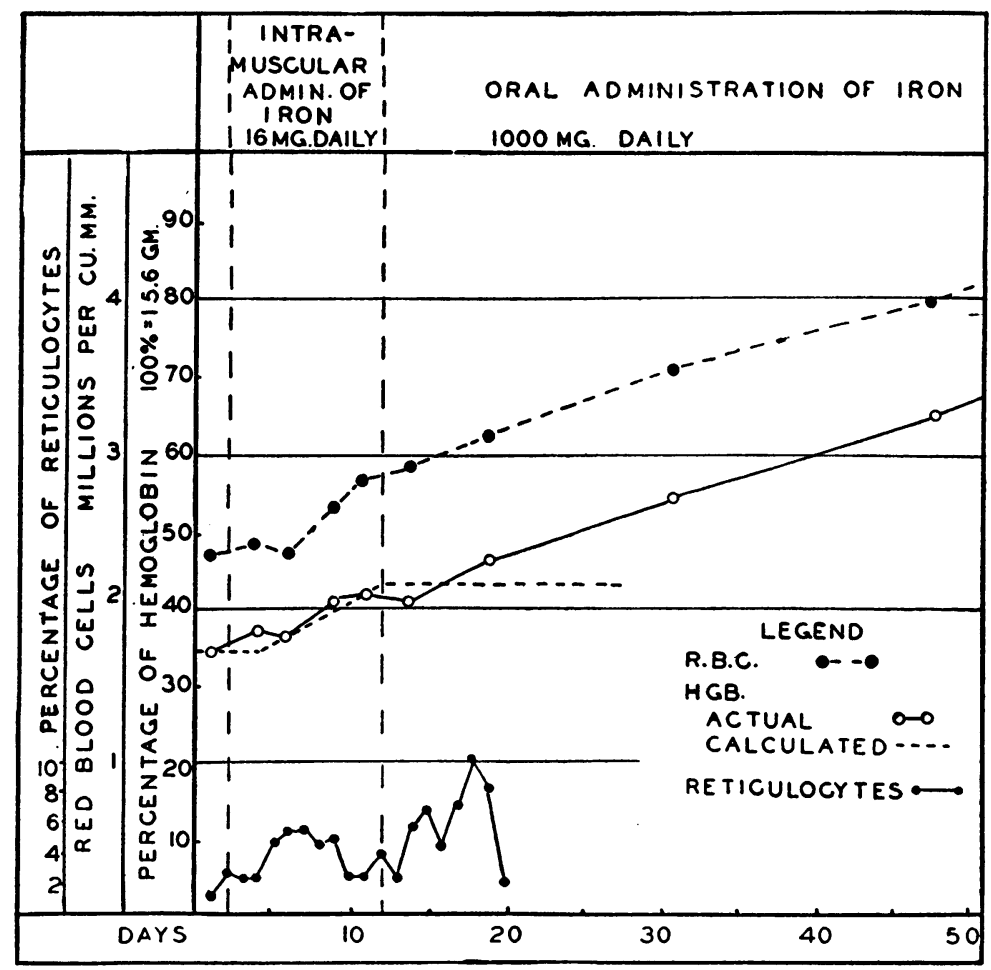

Fig. 1. Case 7, Illustrating the Response of the Reticulocytes, the Hemoglobin and the Red Blood Cells First to Iron Administered Intramuscularly in Small Dosage, Second to Iron Administered Orally in LARGe Dosage.

The second reticulocyte "peak" is indicative of a greater effect of the oral dosage of iron. Note the close correlation between the actual hemoglobin rise and the rise which is calculated from the total amount of iron given to the patient by injection (see text).

TABLE 3

Comparison of the mean rates of hemoglobin rise following first parenteral and then oral iron administration in 10 cases of hypochromic anemia

\begin{tabular}{|c|c|c|c|c|}
\hline \multirow[b]{2}{*}{ 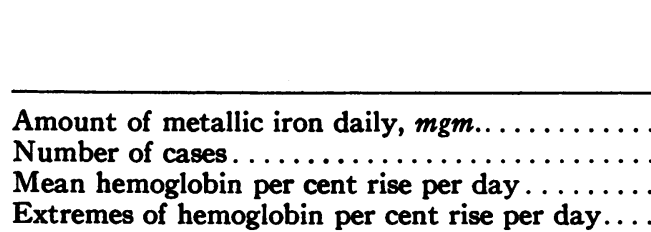 } & \multicolumn{3}{|c|}{ Parenteral iron administration } & \multirow{2}{*}{$\begin{array}{c}\begin{array}{c}\text { Oral iron } \\
\text { adminis- } \\
\text { tration }\end{array} \\
837 \\
10 \\
1.3 \\
0.6-2.8\end{array}$} \\
\hline & $\begin{array}{c}8 \\
5 \\
0.3 \\
0-0.6\end{array}$ & $\begin{array}{c}16 \\
2 \\
0.5 \\
0.5-0.5\end{array}$ & $\begin{array}{c}32 \\
3 \\
1.9 \\
0.8-2.0\end{array}$ & \\
\hline
\end{tabular}


that a dose of $1,000 \mathrm{mgm}$. of metallic iron a day given orally is somewhat more effective than a dose of $32 \mathrm{mgm}$. given parenterally. However, from the information furnished by the rate of the hemoglobin rise the opposite conclusion may be drawn. Further information may be gained by the application of a more refined test for the adequacy of the blood response to iron administration.

From data to be published (7), certain standards for satisfactory hemoglobin and reticulocyte responses following iron in hypochromic anemia have been established. The standard for the hemoglobin response after iron in hypochromic anemia has been determined from the mean of the hemoglobin responses of eighty cases of hypochromic anemia during the oral administration of iron. This standard is about 2 per cent of hemoglobin per day when the initial hemoglobin level is below 50 per cent, and thus in a case of hypochromic anemia a very rapid hemoglobin regeneration and, therefore, an adequate dose of iron is necessary to meet the requirement. The standard for the reticulocyte response has been adopted from data given by Minot and Heath (3) who have shown that the height of the reticulocyte response in hypochromic anemia, after adequate iron therapy, is inversely proportional to the initial level of the red blood cells per cu. mm. and the hemoglobin percentage. The response of the blood in a case of hypochromic anemia may be considered as a mean percentage of the expected response based upon these standards for hemoglobin and reticulocytes.

Table 4 gives the percentage of the expected response of the hemoglobin and reticulocytes of all seventeen cases based upon these standards. The lowest mean response was obtained with the smallest dose of iron

TABLE 4

The response of the hemoglobin and the reticulocytes after iron therapy

(The figures given are a mean per cent of the expected rise of hemoglobin and reticulocytes based upon arbitrary standards)

\begin{tabular}{|c|c|c|c|c|c|}
\hline \multirow[b]{2}{*}{$\begin{array}{l}\text { Amount of metallic iron daily, mgm..... } \\
\text { Number of cases } \ldots \ldots \ldots \ldots \ldots \ldots \ldots \\
\text { Mean per cent of expected response.... } \\
\text { Extremes of mean per cent of expected } \\
\quad \text { response } \ldots \ldots \ldots \ldots \ldots \ldots \ldots \ldots \ldots \\
\text { Per cent of cases attaining a mean per } \\
\text { cent of expected response of more than } \\
\quad 100 \ldots \ldots \ldots \ldots \ldots \ldots \ldots\end{array}$} & \multicolumn{3}{|c|}{ Parenteral iron administration } & \multicolumn{2}{|c|}{ Oral iron administration } \\
\hline & $\begin{array}{r}8 \\
5 \\
25 \\
\\
3-39\end{array}$ & $\begin{array}{r}16 \\
2 \\
40 \\
\\
26-54\end{array}$ & $\begin{array}{c}32 \\
10 \\
85 \\
50-130\end{array}$ & $\begin{array}{c}100-200 \\
16 \\
82 \\
35-165\end{array}$ & $\begin{array}{c}1,000 \\
38 \\
89 \\
40-195\end{array}$ \\
\hline
\end{tabular}

given parenterally, namely, $8 \mathrm{mgm}$. daily. The highest mean response, 85 per cent of the expected, standard response, was obtained in the cases receiving the largest dose of iron parenterally. This response compares 
favorably with the response of an additional group of cases of hypochromic anemia receiving large amounts (6 grams daily) of iron and ammonium citrate orally. It will be seen in Table 4 that the mean response of the cases receiving 100 to $200 \mathrm{mgm}$. of iron orally was only slightly smaller than that of the cases receiving $1,000 \mathrm{mgm}$. orally, but as has been explained elsewhere (7) the oral dose of $1,000 \mathrm{mgm}$. of iron a day is to be regarded as a much more effective dosage than the smaller amounts, when individual patients are concerned. A dose of iron and ammonium citrate by mouth containing less than $100 \mathrm{mgm}$. of iron daily may produce a satisfactory blood response in an occasional patient, but is much more apt to result in an unsatisfactory response or no response. Among the cases receiving large doses of iron parenterally and $1,000 \mathrm{mgm}$. orally, a similar proportion of each group attained responses of over 100 per cent: 40 per cent of the ten cases receiving $32 \mathrm{mgm}$. or more of iron parenterally attained hemoglobin and reticulocyte responses of over 100 per cent, and 42 per cent of the thirty-eight cases receiving $1,000 \mathrm{mgm}$. of iron by mouth attained responses of over 100 per cent.

It is therefore considered that a daily dose of $1,000 \mathrm{mgm}$. of metallic iron given orally in the form of iron and ammonium citrate is approximately equivalent in its blood-building power to a daily dose of $32 \mathrm{mgm}$. of metallic iron given parenterally in the form of iron and ammonium citrate to patients with hypochromic anemia.

The experiments, of course, bring out a tremendous difference in the mass of metallic iron given by the two routes. This is interesting in comparison with pernicious anemia, in which it has been observed that the effective amount of potent material, when injected, is many times smaller than when given by mouth (8), (9). One thousand mgm. of iron orally is the customary daily dose when iron and ammonium citrate is employed in this clinic, and represents a dose of 6 grams of the salt which is divided into three portions. As little as $85 \mathrm{mgm}$. of iron orally has occasionally, but not as a rule, been found to be very effective (7). On the other hand, a dose of $2,000 \mathrm{mgm}$. of iron daily has occasionally been found necessary to produce a maximal response, particularly in individuals who have low acidity of the gastric contents. The kind of iron administered orally is also of considerable significance in judging the dosage. The necessary dose of reduced iron is very high (1 to 10 grams) (10), (11), and that of organic iron preparations is probably also high (12). Reimann and Fritsch (13) have demonstrated that ferrous salts are more effective than ferric salts. They have obtained undoubtedly good results with as little as 22 to $100 \mathrm{mgm}$. of iron in the form of ferrous chloride given daily by mouth.

The practical aspects of the oral and the parenteral administration of iron to patients is a problem of an entirely different nature. Iron salts are very cheap, and there is no financial objection to the use of large doses 
by mouth, as there is to the use of large doses of liver extract in the treatment of pernicious anemia. Indeed, the actual expense to the patient of intravenous injections of ineffective doses of iron, which are recommended by some physicians, must be absurdly high as compared with the low cost of a simple and very potent iron salt given by mouth, such as iron and ammonium citrate or ferrous carbonate. However, this is not as important as the discomfort to the patient of administering iron parenterally. Thirty-two mgm. is at least double the maximum dose of green iron citrate recommended in New and Non-Official Remedies, and the data presented in this paper indicate that even this amount daily is not an optimal quantity for many cases. This dose intramuscularly is attended by severe local symptoms lasting about twenty-four hours, and also by general symptoms of a very disagreeable nature which may be dangerous, as has been described. It is therefore considered that, except in rare instances, the administration of iron by the parenteral route should be avoided.

\section{The utilization of iron administered parenterally}

In studying the data for the first ten cases, it was discovered that the calculated amount of iron in the hemoglobin gained bore a close relationship to the amount of iron injected. In order to determine this relationship more accurately, it was necessary to give parenteral injections for a number of days, followed by a control period in which no iron was given, and in which the complete rise of hemoglobin could be observed. Table 5 is a summary of the results obtained in seven cases. Cases 11, 12 and 13 were given several courses of iron administered parenterally. In all instances there was an appreciable rise of reticulocytes. In all but Case 17 there was a hemoglobin response. In Case 17 there was moderate sepsis present in the form of bronchiectasis, and poor co-operation by the patient necessitated giving only a small amount of iron. In Case 12 pyelitis accompanied by a low grade fever prevented as rapid a hemoglobin response as is ordinarily observed, but a satisfactory result was at length attained.

In order to determine the total amount of hemoglobin formed as a result of iron treatment it was necessary to know the patient's blood volume. This was determined in Cases 11, 12, 13, 14 and 15. The average blood volume per square meter of body surface of these five cases was used in estimating the blood volume of the other cases. This was $2,423 \mathrm{cc}$. per square meter of body surface, a figure somewhat lower than that reported by Rowntree, Brown, and Roth (4) for secondary anemia, but probably more desirable for this series, not only because the patients had a greater degree of anemia than those of Rowntree, Brown and Roth, but also for the sake of uniformity of methods.

The patients were all maintained upon diets that did not contain 


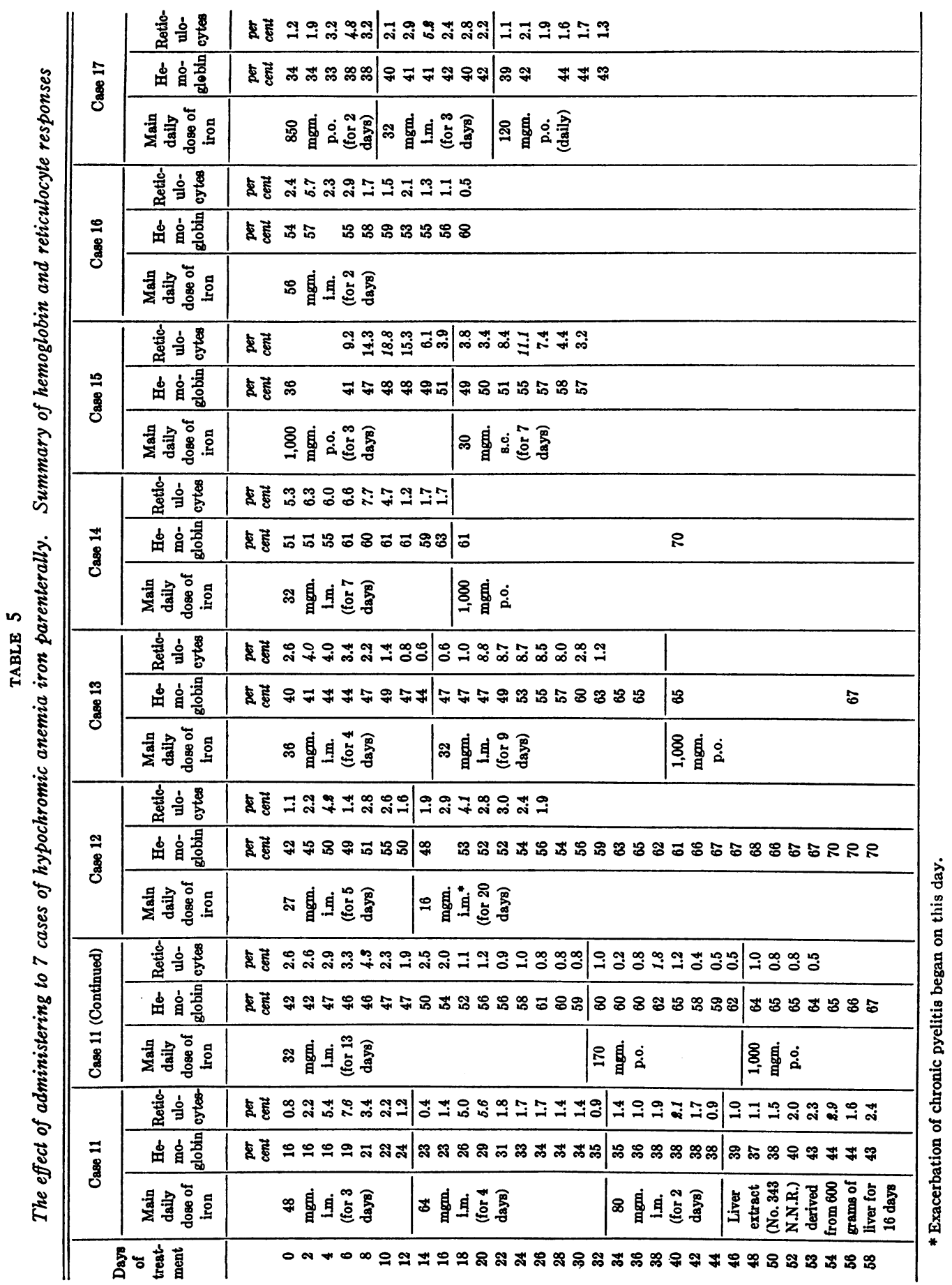


meat. Although it was not known whether or not the patients were in iron balance, this was presumed to be approximately the case, provided that the control periods showed no hemoglobin regeneration. The amount of iron in hemoglobin may be considered conveniently as 0.3 per cent (14), a figure which checks closely with that obtained from the oxygen capacity of the blood if hemoglobin combines with one molecule of oxygen per atom of iron (15). From these data the total amount of circulating hemoglobin, and also of iron in the hemoglobin, may be easily calculated. The total amount of iron gained by the circulating hemoglobin after iron therapy is the difference between the final total amount of iron in the circulating hemoglobin and the total amount before iron therapy. If the total amount of iron given to the patient is known, the percentage of utilization of this iron for the building of new hemoglobin is easily ascertained by dividing the grams of iron gained $(X 100)$ by the grams of iron injected.

Table 6 gives the results of these determinations upon all the cases excepting Cases 1, 5, and 17. Cases 1 and 17 had no demonstrable rise

TABLE 6

The utilization of iron administered parenterally

\begin{tabular}{c|c|c|c|c|c}
\hline \hline Case number & $\begin{array}{c}\text { Period } \\
\text { of iron } \\
\text { injection }\end{array}$ & $\begin{array}{c}\text { Iron in } \\
\text { circulating } \\
\text { hemoglobin }\end{array}$ & Iron injected & $\begin{array}{c}\text { Iron gained in } \\
\text { circulating } \\
\text { hemoglobin }\end{array}$ & $\begin{array}{c}\text { Per cent of } \\
\text { utilization of } \\
\text { injected iron }\end{array}$ \\
\hline & & grams & grams & grams & per cent \\
2 & 1 & .514 & .080 & .084 & 105 \\
3 & 1 & .429 & .096 & .108 & 112 \\
4 & 1 & .486 & .080 & .123 & 154 \\
6 & 1 & .432 & .144 & .146 & 101 \\
7 & 1 & .626 & .160 & .128 & 80 \\
8 & 1 & .341 & .320 & .225 & 70 \\
9 & 1 & .663 & .304 & .211 & 69 \\
10 & 2 & .994 & .256 & .161 & 66 \\
11 & 1 & .636 & .224 & .281 & 125 \\
& 1 & .332 & .144 & .118 & 82 \\
& 2 & .450 & .256 & .248 & 97 \\
12 & 3 & .698 & .160 & .137 & 86 \\
13 & 4 & .835 & .416 & .276 & 66 \\
14 & 1 & .609 & .136 & .131 & 96 \\
15 & 2 & .740 & .320 & .259 & 81 \\
16 & 1 & .582 & .144 & .126 & 87 \\
& 2 & .708 & .288 & .388 & 135 \\
& 1 & .883 & .224 & .231 & 103 \\
& 1 & 1.074 & .209 & .165 & 79 \\
& 1 & 1.137 & .112 & .085 & 76 \\
\hline
\end{tabular}

of hemoglobin and therefore did not utilize the injected iron for reasons which have been explained. In Case 5 the number of hemoglobin determinations were insufficient. On Figures 1 and 2 the broken lines represent the calculated response of the hemoglobin to the amount of iron 
injected, assuming that the hemoglobin began to rise after the second day at a rate of 1 per cent per day. The close relationship of the actual to the calculated gain of hemoglobin is striking, and is especially well illustrated in Figure 2. It is evident that the error involved, however, in determining the percentage of utilization when only small amounts of iron are given is so great that it detracts considerably from the significance of the results.

Case 11, a female with idiopathic hypochromic anemia with achlorhydria and with an associated dysphagia (Plummer-Vinson syndrome), deserves particular attention. The course of the recovery from anemia in this case is shown in Figure 2. Following the third course of iron injections she was given liver extract number 343 (N. N. R.) in a daily amount which was derived from 600 grams of liver. This was given in the belief that such cases may be anemias due not exclusively to iron deficiency, but forms that respond not only to iron but also, to a less extent, to some of the substances present in liver extracts. The patient did have a slight reticulocyte response and a moderate hemoglobin rise during this period of liver therapy which, however, was not sustained. It was thought that since liver extract number 343 (N. N. R.) contains very slight amounts of iron this did not interfere with the observations on the effectiveness of the iron therapy. Indeed, the giving of liver extract to this patient may have removed at least some increments of the anemia which were not directly due to iron starvation, and thus have allowed a more complete response to the iron. It is probable that if certain other extracts of liver, effective in hypochromic anemia, had been given, a greater response would have occurred. However, such extracts are known to contain appreciable amounts of iron which would probably account for the greater response in such a patient.

The average utilization of parenteral iron in all cases was 96 per cent, the extremes being 69 and 154 per cent. Unobserved variations in blood volumes, many of which, it must be recalled, were estimated, and inaccuracies of hemoglobin determination are probably the chief factors which account for these wide extremes. Notwithstanding the errors, the figures indicate an extraordinarily close relationship between the amount of iron injected and the amount gained in the circulating hemoglobin. This is shown graphically in Figure 3. Attention is called particularly to the four encircled dots in this figure, corresponding to the four periods of treatment of Case 11, which show a greater gain of hemoglobin with each increase in the amount of iron administered.

The comparison of the percentage of utilization of iron given parenterally with that of iron given by mouth is interesting. When very small amounts of iron are given by mouth it is possible in a few instances to attain over 50 per cent utilization as determined in this manner (7). However, in the treatment of many cases over long periods of time, and 

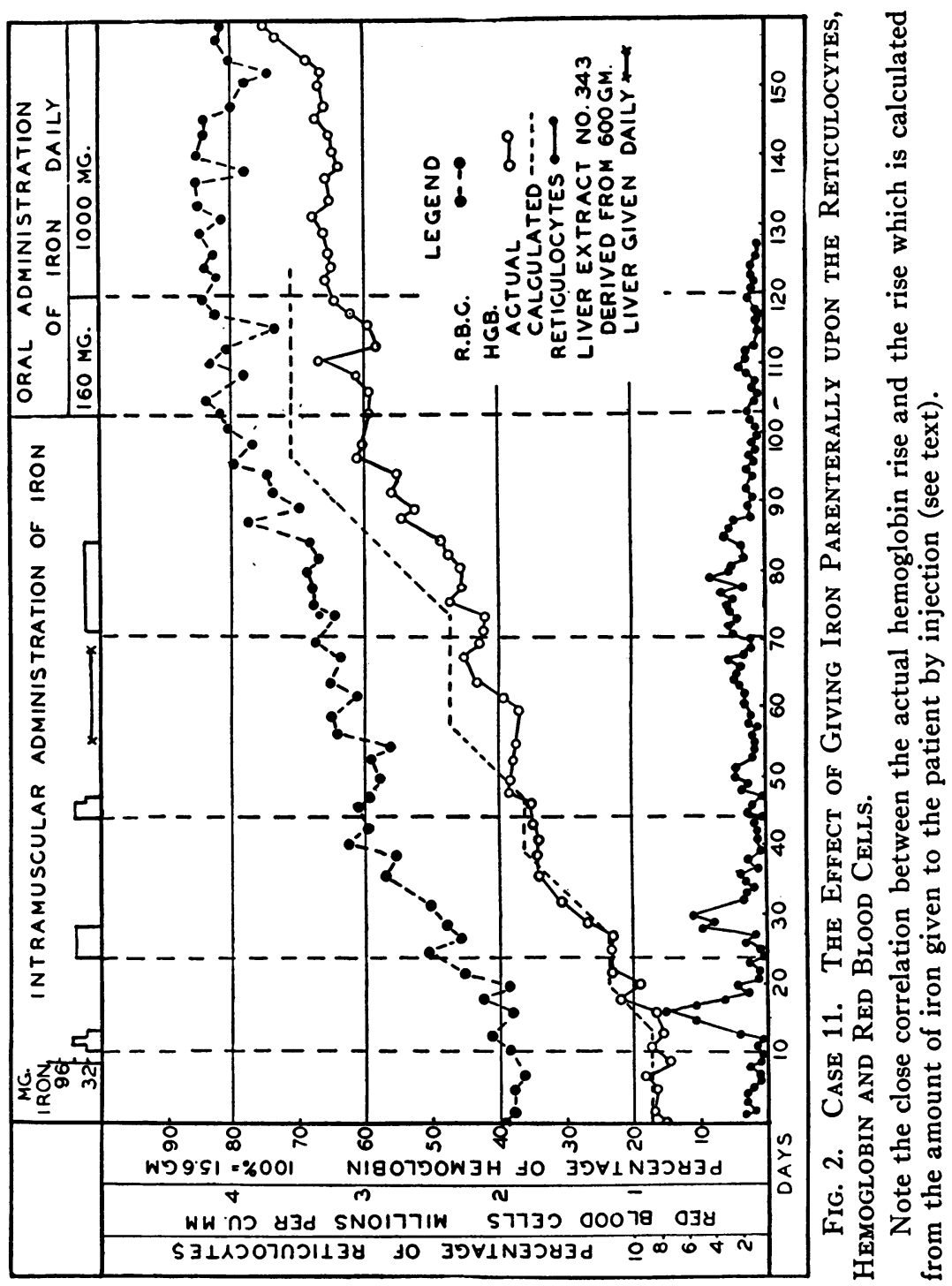
with the usual large doses of iron given by mouth, the utilization is only a little over 3 per cent. No utilization over 100 per cent has yet been observed when iron has been given by mouth. Presumably, a percentage of utilization of "154," which was calculated in Case 4, is the result of unobserved changes in blood volume together with errors in technique. If, however, it were a true value, it would suggest a number of perplexing problems. Whether or not a percentage of utilization of over 100 in certain cases can possibly mean some "stimulating" action of iron, whether or not, in what is believed to be a true iron deficiency, the injected iron is all retained by the body, and whether or not the iron injected merely makes

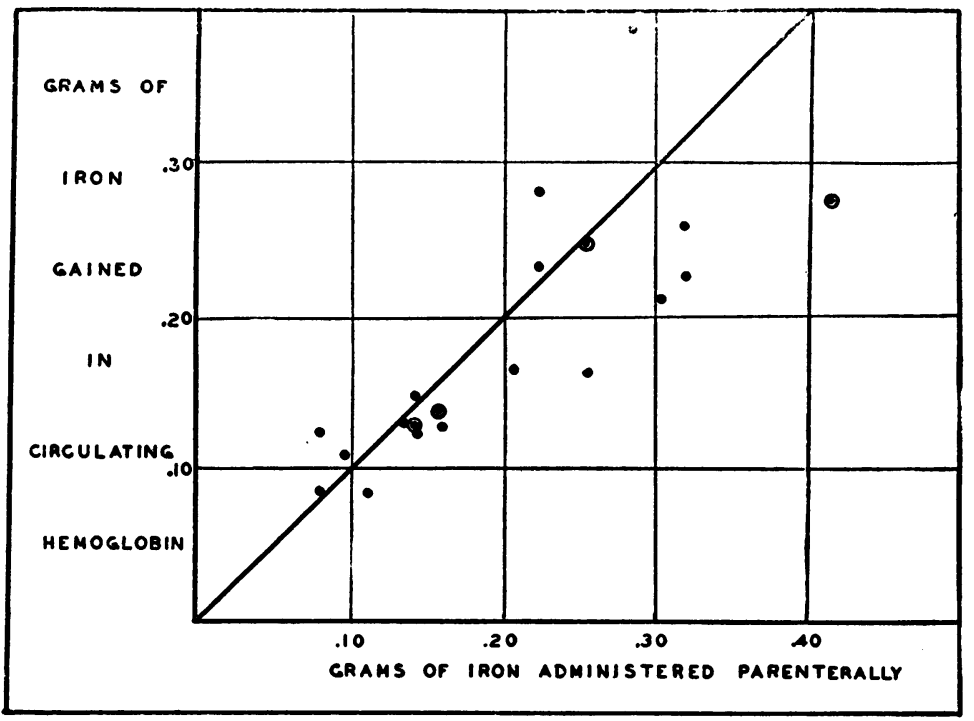

Fig. 3. The Relationship between the Grams of Iron Administered Parenterally and the Grams of Iron Gained in the Circulating Hemoglobin in 20 Observations upon 14 Patients.

The oblique line represents ideal correlation, or 100 per cent utilization of iron injected. Note the four encircled dots which represent the four periods of iron injection in Case 11, showing a greater amount of iron recovered in the circulating hemoglobin with each greater amount of iron injected.

available other sources of iron in the body for hemoglobin formation are some of the problems awaiting solution. However, it seems justifiable to come to the following conclusion: the amount of iron (within certain maximum limits) given parenterally in hypochromic anemia corresponds closely to the amount of iron gained in the circulating hemoglobin, and is apparently utilized to a very large extent in the building of new hemoglobin.

The corollary to this conclusion is that the daily dose of parenteral iron must be of the same magnitude as the amount of iron in the desired daily rise of hemoglobin. A conservative estimation of a satisfactory rise 
of hemoglobin, based upon the experience gained from treating many cases of hypochromic anemia, is about 1 per cent of hemoglobin a day. For an individual with a constant blood volume of $5,000 \mathrm{cc} ., 1$ per cent of hemoglobin a day would mean a gain each day of 7.8 grams of hemoglobin containing $23.4 \mathrm{mgm}$. of iron. A daily parenteral dose of this amount of iron is somewhat smaller than the dose of $32 \mathrm{mgm}$. which, as was demonstrated above, is approximately equivalent in effectiveness to a daily oral dose of $1,000 \mathrm{mgm}$. of iron in the form of iron and ammonium citrate.

It is therefore evident that there is no distinct advantage in giving iron parenterally. It is not uncommon to observe a sustained rate of hemoglobin formation of over 2 per cent a day during the oral administration of large doses of iron. Such a rate would generally require more than $32 \mathrm{mgm}$. of iron given daily by injection, and more than could be considered a safe dose to administer at one time. Weekly or biweekly injections of iron, especially when minute doses are given, are to be deplored as practically useless. Perhaps further work will show that a few cases of hypochromic anemia having complications, or intestinal abnormalities, will be benefited by parenterally administered iron when oral administration fails. Also occasionally some psychic factor may prevent the administration of iron by mouth, and then the cautious use of iron parenterally may be found of distinct value.

\section{COMMENT}

For many years it has been recognized that iron given parenterally is an effective therapeutic agent in certain forms of anemia (16), (17), (18), (19), (20). It is known that the dose of iron so administered must be small, because of toxic effects (21). The fatal dose of iron injected subcutaneously into animals is quite small, and has been estimated to be about 30 to $60 \mathrm{mgm}$. per kilo (22). Starkenstein (23) determined the relation of the toxicity by parenteral administration to that of enteral administration to be, for the ferrous salts, $1: 5$ to $1: 10$, and, for the complex iron salts, $1: 100$. However, the appropriate dose of parenterally administered iron in man has never been clearly defined. Stockman (17) found that a dose of 16 to $32 \mathrm{mgm}$. of iron subcutaneously a day was effective in abolishing anemia in chlorosis. Witts (1) stated that chlorosis could be alleviated by the injection of 1 to 2 grains of iron and ammonium citrate in 5 to 10 per cent solution daily, that is, 10 to $20 \mathrm{mgm}$. of metallic iron daily. Witts, however, criticized strongly the current tendency to employ for parenteral use unofficial preparations of iron containing infinitesimal amounts of iron.

A great deal of work has been done upon the deposition and excretion of injected iron. It may be stored in animals mostly in the liver and spleen (24), (25), (26). It is excreted by the bowel (27) and by the 
kidneys (17), (28). Whether or not, in anemic individuals, injected iron is stored, excreted, or utilized in the newly formed circulating hemoglobin has not been satisfactorily demonstrated. Stockman (17) found that in cases of chlorosis which were given iron subcutaneously, iron in increased amounts was found in the urine invariably, and therefore he believed that all the iron was not utilized in the formation of new hemoglobin.

The study of the present experiments inevitably leads to the belief, without establishing the absolute proof, that iron given therapeutically in hypochromic anemia is supplying a deficiency, and is thus being made available for the normal manufacture of necessary hemoglobin molecules. This point of view gives a logical explanation of the etiology of hypochromic anemia, and provides a simple basis for further experimental work upon this condition. This is a much simpler explanation than the one which assumes that iron, like arsenic or copper, has only a "stimulating," "catalytic" or "tonic" effect upon hemoglobin formation. It is very likely that the reticulocyte response, attributed to the effect of iron, may not be a direct one, but one due to the supply of hemoglobin to the young red blood cells. The delay of about four days usually encountered before the appearance of increased numbers of reticulocytes, following the administration of a potent substance in anemia, can be understood if this time is required for certain new molecules necessary to cell growth to be formed. Iron may "stimulate" in this sense the growth of young red blood cells.

It is not believed that poverty of hemoglobin is the only result of such an iron deficiency, although it is likely that the body economy can best spare iron from the hemoglobin molecule before it gives up iron from the fixed tissues of the body. Whipple (29), for example, has shown that it is difficult to exhaust muscle hemoglobin which is closely related to blood hemoglobin. Iron is known to be present in many, if not in all, cells (30), (31) both plant and animal; but the relatively large amount of iron in the red blood cells, and the ease of observing changes in the corpuscular characteristics of the blood, has focussed our attention upon this part of the body. The dystrophy of the nails commonly observed in idiopathic hypochromic anemia with achlorhydria is very possibly the result of a poor supply of iron to the germinative cells of the nail root. One is tempted also to place under this etiology, certain other changes observed in these patients: atrophy of the skin, atrophic changes of the tongue, fissures about the mouth, and perhaps also certain blood capillary changes which lead to easy bruising and menorrhagia. All of these changes have been observed to disappear as the anemia improves during the administration of iron. Therefore a part of injected or assimilated iron may go to supply deficiencies in the body other than in the blood regenerating apparatus. But it is believed that the amount of iron utilized in this way is extremely small as compared to the amount utilized in the manu- 
facture of hemoglobin. Some of the iron may also be excreted in the urine or feces.

Whipple and Robscheit-Robbins (32) have shown a very complete conservation of hemoglobin injected intravenously into dogs, amounting to 90 per cent or even more. Moreover, their work suggests that the body can manufacture certain organic constituents of the hemoglobin molecule (pyrrol substances) (33). The fact that liver and kidney are more effective than iron in regenerating hemoglobin in Whipple's dogs with anemia due to chronic blood loss, whereas these substances are often ineffective in regenerating hemoglobin in idiopathic hypochromic anemia, is explainable from several points of view. The standard ration employed by Whipple and Robscheit-Robbins contains $20 \mathrm{mgm}$. of iron daily, which they regard as adequate for maintenance and more than enough to make up for daily wastage and for hemoglobin lost by bleeding (34). The substances lacking in these dogs, therefore, are probably organic rather than inorganic. In idiopathic hypochromic anemia a deficiency of iron seems to be the chief factor in preventing adequate regeneration of hemoglobin. In other forms of hypochromic anemia, especially that following uncomplicated chronic blood loss, the administration of liver may be followed by as satisfactory blood regeneration as when only iron is employed, although the administration of both liver and iron in certain cases is sometimes more satisfactory than either alone (35). In such conditions, as in Whipple's dogs, the substances preventing adequate hemoglobin regeneration may be principally organic. Because a utilization of more than 100 per cent of the administered iron has not been demonstrated satisfactorily there seems to be no definite evidence of a "catalytic" influence or "salt effect" of iron in the production of hemoglobin in human anemia.

As Whipple has aptly expressed it "... iron is an elusive sprite ... ," and in spite of a voluminous literature representing countless experiments, we are far from reaching a final conclusion in problems concerning iron metabolism. However, as observations upon patients and upon experimentally produced anemia accumulate, it becomes possible to formulate certain basic principles which aid in the classification and alleviation of anemia. The present experiments give evidence to prove that, in what has been considered iron deficiency, the deficient substance, when given by the parenteral route, may be quantitatively recovered in an organized form in the blood stream. As our knowledge of chemical processes progresses, the quantitative relationships of vitamins and other necessary food substances to deficiencies will become more accurately known. 


\section{SUMMARY AND CONCLUSIONS}

1. Seventeen consecutive cases of hypochromic anemia have been studied in reference to hemoglobin regeneration and reticulocyte response following the administration of iron parenterally and orally.

2. A daily dose of $1,000 \mathrm{mgm}$. of metallic iron given orally in the form of iron and ammonium citrate is approximately equivalent in its bloodbuilding power to a daily dose of $32 \mathrm{mgm}$. of metallic iron given parenterally in the form of iron and ammonium citrate to patients with hypochromic anemia.

3. The amount of iron given parenterally (within certain maximum limits) corresponds closely to the amount of iron gained in the circulating hemoglobin, and is apparently utilized to a very large extent in the building of new hemoglobin.

4. Because of the toxicity of iron administered parenterally in adequate dosage, and for practical and economic reasons, it is believed that it is undesirable to give iron parenterally rather than orally in most cases.

5. A simple explanation is offered for the etiology and the effectiveness of iron therapy in certain types of hypochromic anemia, namely, that these types of anemia are due to a deficiency, chiefly of iron, preventing adequate hemoglobin formation. The relationship of the deficient substance, iron, to the deficiency itself, which is mainly in the circulating hemoglobin, can be expressed in a quantitative fashion.

\section{BIBLIOGRAPHY}

1. Witts, L. J., Proc. Royal Soc. Med., 1931, xxiv, 543. Discussion on the Therapeutic Uses of Iron.

2. Dameshek, W., Am. J. Med. Sci., 1931, clxxxii, 520. Primary Hypochromic Anemia (Erythro-Normoblastic Anemia).

3. Minot, G. R., and Heath, C. W., Am. J. Med. Sci., 1932, clxxxiii, 110. The Response of the Reticulocytes to Iron.

4. Rowntree, L. G., Brown, G. E., and Roth, G. M. The Volume of the Blood and Plasma in Health and Disease, W. B. Saunders Company, Philadelphia and London, 1929.

5. Castle, W. B., Heath, C. W., and Strauss, M. B., Am. J. Med. Sci., 1931, clxxxii, 741. Observations on the Etiologic Relationship of Achylia Gastrica to Pernicious Anemia. IV.

6. Mettier, S. R., and Minot, G. R., Am. J. Med. Sci., 1931, clxxxi, 25. The Effect of Iron on Blood Formation as Influenced by Changing the Acidity of the Gastroduodenal Contents in Certain Cases of Anemia.

7. Heath, C. W., The Oral Administration of Iron in Hypochromic Anemia. Arch. Int. Med., In press.

8. Gänsslen, M., Klin. Wchnschr., 1930, ix, 2099. Ein hochwirksamer, injizierbarer Leberextrakt.

9. Castle, W. B., and Taylor, F. H. L., J. Am. Med. Assoc., 1931, xcvi, 1198. Intravenous Use of Extract of Liver: Maximal Responses of Reticulocytes from a Single Injection Derived from One Hundred Grams of Liver. Preliminary Communication. 
10. Meulengracht, E., Acta med. Scandinav., 1923, lviii, 594. Large Doses of Iron in the Different Kinds of Anaemia in a Medical Department.

11. Schulten, H., München. med. Wchnschr., 1930, lxxvii, 355. Zur Behandlung hypochromer Anämien mit maximalen Eisendosen.

12. Elvehjem, C. A., J. Am. Med. Assoc., 1932, xcviii, 1048. The Relative Value of Inorganic and Organic Iron in Hemoglobin Formation.

13. Reimann, F., and Fritsch, F., Ztschr. f. klin. Med., 1930, cxv, 13. Vergleichende Untersuchungen zur therapeutischen Wirksamkeit der Eisenverbindungen bei den sekundären Anämien.

14. Murphy, W. P., Lynch, R., and Howard, I. M., Arch. Int. Med., 1931, xlvii, 883. The Value of Determinations of the Iron Content of Whole Blood.

15. Peters, J. P., and Van Slyke, D. D., Quantitative Clinical Chemistry. I. Interpretations, The Williams and Wilkins Company, Baltimore, 1931, p. 519.

16. Rosenthal, M., Wien. med. Presse, 1872, xiii, 6. Ueber das Glyzerin als Lösungsmittel für subkutane Injektionsstoffe.

17. Stockman, R., Brit. Med. J., 1893, i, 881, 942. The Treatment of Chlorosis by Iron and Some Other Drugs.

18. Barlow, W. J., and Cunningham, R. L., J. Am. Med. Assoc., 1911, lvii, 1435. Effects of Hypodermic Injection on the Secondary Anemia of Chronic Pulmonary Tuberculosis.

19. Bullock, E. S., and Peters, L. S., J. Am. Med. Assoc., 1911, lvii, 1428. The Use of Hypodermics of Citrate of Iron in the Secondary Anemia of Tuberculosis.

20. Seiler, F., Deutsche med. Wchnschr., 1911, xxxvii, 1340. Ueber die Rolle des Arseniks bei der Behandlung der Chlorose.

21. Meyer, H., and Williams, F., Arch. f. exper. Path. u. Pharmakol., 1881, xiii, 70. Ueber acute Eisenwirkung.

22. Morawitz, P., München. med. Wchnschr., 1924, 1xxi, 1266. Ueber Eisenund Arsenpräparate.

23. Starkenstein, E., Arch. f. exper. Path. u. Pharmakol., 1927, cxxvii, 101. Uber die Resorbierbarkeit von Eisenverbindungen aus dem Verdauungskanal.

24. Williamson, C. S., and Ets, H. N., Arch. Int. Med., 1925, xxxvi, 333. The Value of Iron in Anemia.

25. Polson, C. J., J. Path. and Bact., 1929, xxxii, 247. Fate of Colloidal Iron Administered Intravenously.

26. Cappell, D. F., J.'Path. and Bact., 1930, xxxiii, 175. The Late Results of Intravenous Injection of Colloidal Iron.

27. Meinertz, J., Zentralbl. f. d. ges. Physiol. u. Path. d. Stoffwechs., 1907, ii, 652, 689. Über den Eisenstoff wechsel.

28. Henriques, V., and Roland, H., Biochem. Ztschr., 1928, cci, 479. Zur Frage des Eisenstoffwechsels.

29. Whipple, G. H., Am. J. Physiol., 1926, lxxvi, 708. The Hemoglobin of Striated Muscle. II. Variations Due to Anemia and Paralysis.

30. Mouneyrat, M. A., Compt. rend. Acad. d. sc., 1907, cxliv, 1067. Du fer dans les tissus végétaux et animaux.

31. Jones, H. W., Biochem. J., 1920, xiv, 654. The Distribution of Inorganic Iron in Plant and Animal Tissues.

32. Whipple, G. H., and Robscheit-Robbins, F. S., Am. J. Physiol., 1927, lxxxiii, 60. Blood Regeneration in Severe Anemia. X. Assimilation 
and Conservation of Bile Pigment, Blood Hemoglobin and Muscle Hemoglobin.

33. Hawkins, W. B., Sribhishaj, K., Robscheit-Robbins, F. S., and Whipple, G. H., Am. J. Physiol., 1931, xcvi, 463. II. Bile Pigment and Hemoglobin Interrelation in Anemic Dogs.

34. Whipple, G. H., and Robscheit-Robbins, F. S., Am. J. Physiol., 1930, xcii, 362. Blood Regeneration in Severe Anemia. XVI. Optimum Iron Therapy and Salt Effect.

35. Keefer, C. S., and Yang, C., Arch. Int. Med., 1931, xlviii, 537. The Treatment for Secondary Anemia: A Study of the Results in One Hundred and Twenty-Six Cases. 